\title{
Transient systolic anterior motion after mitral valve repair: Does it affect long-term outcomes?
}

Niv Ad, MD

See related article on pages 471-6.

Systolic anterior motion (SAM) after mitral valve repair is a widely recognized phenomenon, occurring in an estimated $2 \%$ to $14 \%$ of cases of mitral valve repair. ${ }^{1}$ An incidence of $11 \%$ has been reported after mitral valve repair for degenerative disease. ${ }^{2}$ Anatomic risk factors for SAM are well established and include a short coaptation-septal distance, a low anterior-to-posterior leaflet ratio, redundant elongated leaflets, and septal hypertrophy. ${ }^{3}$ Hemodynamic risk factors for SAM after mitral valve repair are hypercontractility, tachycardia, hypovolemia, and decreased afterload. Surgical decisions related to ring selection and sizing may also play a role. SAM that occurs after mitral valve repair is often well tolerated by patients and in most cases can be resolved with basic interventions that include discontinuation of inotropes, administration of beta-blockers, and volume loading. ${ }^{2}$

In this issue, Kuperstein and colleagues ${ }^{4}$ present their experience with SAM after mitral valve repair. In their report, $8.2 \%$ of patients were identified as having SAM, of which $10 \%$ (5 patients) required an immediate surgical intervention. The authors clearly demonstrate the effectiveness of the hemodynamic maneuvers mentioned, as well as the comparability of their patients' perioperative and late outcomes to those of patients who did not develop SAM. Their study raises important questions:

1. What is the best way to assess the clinical significance of intraoperative SAM?

2. What is the impact of transient intraoperative SAM on long-term outcomes, and how should it be assessed?

Clinical decision making for the management of intraoperative SAM is inherently challenging. The most common approach to assess its significance employs the previously mentioned measures, which include administration of beta-blockers, discontinuation of inotropic support, and

\footnotetext{
From the Department of Cardiac Surgery, Inova Heart and Vascular Institute, Falls Church, Virginia.

Disclosures: Author has nothing to disclose with regard to commercial support. Received for publication Oct 22, 2014; accepted for publication Oct 23, 2014.

Address for reprints: Niv Ad, MD, Department of Cardiac Surgery, Cardiac Surgery Research, Inova Heart and Vascular Institute, 3300 Gallows Rd, Suite 3100, Falls Church, VA 22042 (E-mail: Niv.Ad@Inova.org).

J Thorac Cardiovasc Surg 2015;149:477-8 0022-5223/\$36.00

Copyright (c) 2015 Published by Elsevier Inc. on behalf of The American Association for Thoracic Surgery

http://dx.doi.org/10.1016/j.jtcvs.2014.10.099
}

increase of preload and afterload. ${ }^{5}$ If these conservative measures fail to resolve SAM, immediate surgical intervention is usually required to re-repair or replace the mitral valve. The experience of Kuperstein and colleagues ${ }^{4}$ underscores the benefit of conservative intraoperative measures to identify those patients who are likely to have good outcomes. Still, the currently used decision-making process remains somewhat subjective and is dependent on the experience of the surgeon and the surgical team, leading to potentially inconsistent application of these interventions; some patients may undergo reoperation to address SAM in one center, whereas in another, the same or similar hemodynamic and echocardiographic findings may prompt different clinical decisions.

As the logical next step, what is clearly needed is the development of clinical algorithms to assist in the decisionmaking process. The validation of such a set of algorithms would require prospective evaluation of long-term outcomes. Perhaps the most important contribution of Kuperstein and colleagues ${ }^{4}$ is the unique nature of their follow-up procedure, which not only employs clinical and echocardiographic follow-up but also includes stress echocardiography to serve as a kind of "SAM tolerance test." In their experience, 98\% of patients with documented SAM occurring after mitral valve repair were available for follow-up echocardiography, and $85 \%$ were free of moderate to severe mitral regurgitation at 5 years. Only 2 of the 34 patients who were available for stress echocardiography demonstrated SAM and increased left ventricular outflow obstruction, which resolved with rest and beta-blocker therapy.

This study, ${ }^{4}$ together with others, ${ }^{2,3}$ verifies that conservative intraoperative treatment of SAM is associated with relatively good results at late follow-up. The new information demonstrates that the occurrence of persistent SAM is uncommon, even when maximal provocation is used in the assessment of patients with a history of SAM immediately after mitral valve repair. Our challenge, therefore, should be to establish a more specific decision-making process that will yield a more uniform approach to the relatively common problem of intraoperatively occurring SAM. A clinical algorithm for SAM will probably require a prospective study in which only concrete intraoperative variables are used to formulate the decision of whether to reintervene on the mitral valve or to employ conservative treatment. The approach should also take into account asymptomatic patients who are prone to develop increased mitral regurgitation and left ventricular outflow obstruction secondary to either exercise or stress testing at late follow-up. 


\section{References}

1. Maslow AD, Singh A. Mitral valve repair: to slide or not to slide-precardiopulmonary bypass echocardiogram examination. J Cardiothorac Vasc Anesth. 2006;20:842-6.

2. Brown ML, Abel MD, Click RL, Morford RG, Dearani JA, Sundt TM, et al. Systolic anterior motion after mitral valve repair: is surgical intervention necessary? J Thorac Cardiovasc Surg. 2007;133:136-43.

3. Maslow AD, Regan MM, Haering JM, Johnson RG, Levine RA. Echocardiographic predictors of left ventricular outflow tract obstruction and systolic anterior motion of the mitral valve after mitral valve reconstruction for myxomatous valve disease. J Am Coll Cardiol. 1999; 34:2096-104.

4. Kuperstein R, Spiegelstein D, Rotem G, Stein M, Kogan A, Sternik L, Raanani E. Late clinical outcome of transient intraoperative systolic anterior motion post mitral valve repair. J Thorac Cardiovasc Surg. 2015;149:471-6.

5. Crescenzi G, Landoni G, Zangrillo A, Guarracino F, Rosica C, La Canna G, et al. Management and decision-making strategy for systolic anterior motion after mitral valve repair. J Thorac Cardiovasc Surg. 2009; 137:320-5. 